\title{
Superficial Temporal Artery to Middle Cerebral Artery Bypass and Endovascular Parent Artery Occlusion in the Treatment of Giant Intracranial Aneurysms
}

\author{
Aurélien Ndoumbe ${ }^{{ }^{*}}$, Aimée Redondo ${ }^{2}$ \\ ${ }^{1}$ Faculty of Medicine \& Pharmaceutical Sciences, University of Douala, Douala, Cameroon \\ ${ }^{2}$ Service of Neurosurgery, CHU of Beaujon, Clichy, Paris, France \\ Email: *aurelien.ndoumbe@gmail.com, *aurelen@yahoo.fr
}

How to cite this paper: Ndoumbe, A. and Redondo, A. (2018) Superficial Temporal Artery to Middle Cerebral Artery Bypass and Endovascular Parent Artery Occlusion in the Treatment of Giant Intracranial Aneurysms. Open Journal of Modern Neurosurgery, 8, 147-161.

https://doi.org/10.4236/ojmn.2018.82013

Received: January 2, 2018

Accepted: March 23, 2018

Published: March 26, 2018

Copyright $\odot 2018$ by authors and Scientific Research Publishing Inc. This work is licensed under the Creative Commons Attribution International License (CC BY 4.0).

http://creativecommons.org/licenses/by/4.0/

\section{(c) (i) Open Access}

\begin{abstract}
The authors are reporting on a study drawn from unpublished dissertation done by the corresponding author when he completed his neurosurgical training in Paris, France in 2004, few years before the advent of flow diverters. The study was a retrospective review of giant intracranial aneurysms treated by superficial temporal artery to middle cerebral artery bypass combined with endovascular occlusion of the parent artery. From 1990 to 2003, 29 consecutive cases of giant cerebral aneurysms, not suitable to selective treatment were managed in that way. Twenty-one medical records had enough data to allow objective evaluation. Sixteen female and five male patients bearing 21 giant aneurysms were involved. Their mean age was 46 years. The aneurysm was revealed by mass effect in 13 cases and subarachnoid hemorrhage in one case. On admission 19 patients presented with unruptured aneurysms and two have sustained a subarachnoid hemorrhage. The balloon occlusion test before the bypass operation was not tolerated in 18 patients. The treatment was completed in 19 patients and 17 of them had parent artery occlusion with latex detachable balloons. The only death of the series occurred before the endovascular treatment. The mean follow-up period was 30 months. After completion of the treatment, 16 (84\%) patients had no symptom. Aneurysm recanalization or rupture was not observed after the parent artery occlusion. With the combination of superficial temporal artery to middle cerebral artery bypass + endovascular parent artery occlusion, $90 \%$ of giant intracranial aneurysms untreatable selectively were permanently excluded with a good outcome in $95 \%$.
\end{abstract}

\section{Keywords}

Giant Cerebral/Intracranial Aneurysm, Superficial Temporal Artery to Middle 
Cerebral Artery Bypass, Balloon Test Occlusion, Parent Artery Occlusion, Flow-Diversion

\section{Introduction}

This study was withdrawn from an unpublished dissertation the corresponding author did when he completed his neurosurgical training in Paris in 2004, just before the advent of flow diverters (FD) which have revolutionized the treatment of complex intracranial aneurysms (IAs) [1] [2] [3] [4]. The authors believe that even 13 years later, this work is still of scientific interest, because it allows comparison between an old series with the most recent paradigm shift in the management of complex IAs in general and giant intracranial aneurysms (GIAs) in particular. The paradigm has moved from neurovascular microsurgery towards endovascular coil embolization and now the shift is from embolization to flow diversion [1] [2] [3] [4] [5]. It sounds that FD might become the gold standard for treating complex IAs in the very near future but, flow diversion is not without risks and is far from definitely answering the complex problem presented by the management of complex IAs [5]. Therefore, all treatment modalities remain on the table. Giant intracranial aneurysms are arbitrary defined as those having a size $\geq 25$ millimeters. The natural history of GIAs is dismal because the reported mortality can be as high as $100 \%$ at 2 years after the diagnosis and because neurological morbidity is high in the survivors [5] [6] [7]. The treatment of these lesions is challenging both for neurosurgeons and interventional neuroradiologists. A significant number of GIAs is not suitable neither for direct surgical clipping nor selective embolization, and a vast majority of those which were occluded by embolization at $100 \%$ will recanalize [8]. The coil-embolization often necessitates many procedures with significant procedure related morbidity [9]. In spite of the advent of new endovascular devices such as the balloon assisted technique, stenting, or trispan coils, the optimal treatment of GIAs is not yet defined [5] [9]. Since the introduction of flow diverters such as the Pipeline embolization device (PED) and the SILKstent device in clinical practice, the endovascular management of complex IAs has been tremendously simplified. Nevertheless, the U.S. Food and Drug Administration approval for PED was restricted to unruptured large and GIAs from the internal carotid artery between the superior hypophyseal and cavernous segments [1] [2] [3] [4]. But, data from the literature show that the indications of FD in general and the PED in particular, have been largely expanded. Technical deployment achieved with FD is not $100 \%$ and the procedure-related morbidity and mortality observed with these devices are not null [1] [2] [3] [4] [5]. Therefore, endovascular parent artery occlusion (PAO) with or without a previous extracranial to intracranial (EC-IC) bypass is still a viable treatment option for GIAs [5] [6] [10] [11]. This study reports on a series of 21 cases of GIAs treated by endovascular PAO preceded by superficial tem- 
poral artery to middle cerebral (STA-MCA) bypass.

\section{Patients and Methods}

\subsection{Patients}

From October 1990 to March 2003, 29 consecutive patients with GIAs were treated by PAO with a previous STA-MCA bypass at the neurosurgery service of CHU Beaujon, at Clichy in Paris, France. Selective treatment either endovascular or surgical had failed or was considered too risky or not feasible. As mentioned before, only 21 cases had enough data to be analyzed objectively. They were 16 females and 5 males bearing 21 GIAs of the anterior territory. The following data were collected for every patient: age, gender, past medical history, family history, present complaint, symptoms, findings on physical examination, radiological and biological exams data, result of the balloon test occlusion, date of the STA-MCA bypass operation, time interval between the STA-MCA bypass and the endovascular PAO, clinical events occurring between the STA-MCA bypass and PAO operations, the result of the BOT after the STA-MCA bypass, the date of the PAO, the complications related to the STA-MCA bypass, the complications related to the PAO. For radiological investigation, all patients had CT and CT angiography, MRI + MRA, four vessels digital subtractive angiography (DSA), transcranial Doppler to check the bypass patency. Single photon emission computed tomography (SPECT) was not available in this series. Other exams were done as needed. On admission, all patients had a thorough neurologic examination after which they were graded according to the WFNS, Hunt and Hess and Fisher grading scales (Table 1). After the PAO intervention and discharge from the hospital, patients were followed up in an out-patient setting on regular basis. The clinical outcome was determined at three, six and 12 months after treatment and at the last follow up visit with the modified Rankin scale (mRS) (Table 2). The mRS was rated using structured interviews. The cut-off point between good and poor outcomes was $\leq 2$.

\subsection{The Bypass Operation}

A standard STA-MCA bypass [12] [13] was performed in 20 patients (one failure due to an atheromatous superficial temporal artery), and an OA-MCA bypass in one. At day-1 after surgery, patients were started on Aspirin $250 \mathrm{mg} / \mathrm{day}$ and Persantine $250 \mathrm{mg}$ TID. A Transcranial Doppler (TCD) was done around day- 5 to assess the patency of the anastomosis. Then, the patient was transferred to the interventional neuroradiology unit one week after the bypass to undergo a second BOT and a subsequent PAO. All the clinical events thought to be related to the bypass intervention were recorded.

\subsection{The BOT and PAO}

Before the STA-MCA bypass, the BOT was not tolerated in 18 patients and 3 patients had a functionally insufficient circle of Willis. The BOT was done under 
Table 1. WFNS, Hunt-Hess \& Fisher grading scales.

\begin{tabular}{|c|c|}
\hline \multicolumn{2}{|r|}{ WFNS ANEURYSMAL SAH GRADING SCALE [22] } \\
\hline GRADE & GCS/MOTOR DEFICIT \\
\hline I & 15/absent \\
\hline II & $14-13 /$ absent \\
\hline III & $14-13 /$ present \\
\hline IV & $12-7 /$ present or absent \\
\hline $\mathrm{V}$ & $6-3 /$ present or absent \\
\hline \multicolumn{2}{|r|}{ HUNT \& HESS ANUERYSMAL SAH GRADING SCALE [23] } \\
\hline GRADE & DEFINITION \\
\hline 1 & Mild headache, alert and oriented, minimal (if any) nuchal rigidity \\
\hline 2 & $\begin{array}{l}\text { Full nuchal rigidity, moderate-severe headache, alert \& oriented, no neurological } \\
\text { deficit (besides CN palsy) }\end{array}$ \\
\hline 3 & Lethargy or confusion, mild focal neurological deficits \\
\hline 4 & Stuporous, more sever focal deficit \\
\hline 5 & Comatose, showing signs of severe neurological impairment (ex.: posturing) \\
\hline \multicolumn{2}{|r|}{ FISHER CT SAH GRADING SCALE [24] } \\
\hline GRADE & DEFINITION \\
\hline 1 & No subarachnoid or intraventricular hemorrhage \\
\hline 2 & Diffuse thin $(<1 \mathrm{~mm})$ subarachnoid hemorrhage, no clot \\
\hline 3 & Localized clots and/or layers of blood $>1 \mathrm{~mm}$ in thickness \\
\hline 4 & Diffuse or no SAH, intracerebral or IVH present \\
\hline
\end{tabular}

WFNS: world federation of neurosurgical societies. SAH: subarachnoid hemorrhage. CT: computed tomography. CN: cranial nerve. GCS: Glasgow coma scale. Mm: millimeter. IVH: intraventricular hemorrhage.

Table 2. Modified Rankin scale [25] [26] [27].

\begin{tabular}{|c|c|}
\hline \multicolumn{2}{|r|}{ MODIFIED RANKIN SCALE* } \\
\hline SCORE & DEFINITION \\
\hline 0 & No symptoms \\
\hline 1 & $\begin{array}{l}\text { No significant disability, despite symptoms; able to perform all usual duties } \\
\text { and activities }\end{array}$ \\
\hline 2 & $\begin{array}{l}\text { Slight disability; unable to perform all previous activities but able to look after } \\
\text { own affairs without assistance }\end{array}$ \\
\hline 3 & Moderate disability; requires some help, but able to walk without assistance \\
\hline 4 & $\begin{array}{l}\text { Moderately severe disability; unable to walk without assistance and unable to } \\
\text { attend to own bodily needs without assistance }\end{array}$ \\
\hline 5 & $\begin{array}{l}\text { Severe disability; bedridden, incontinent, and requires constant nursing care } \\
\text { and attention }\end{array}$ \\
\hline
\end{tabular}

*: some clinical trials add a score 6 corresponding to "death". 
local anaesthesia with mild sedation by puncturing the femoral artery at the inguinal site. A retrograde insertion of a micro catheter with an inflatable balloon was performed until it reached the internal carotid artery which was planned to be occluded. The test was done with the patient under intravenous heparin infusion. The criteria for tolerance were as follows:

- No change in the neurological status for 30 minutes;

- Cerebral perfusion time and venous phase appearance delayed no more than 1 second on the side of the occlusion compared to the opposite site;

- No change in clinical status or cerebral perfusion when hypotension was induced.

After the STA-MCA bypass surgery, the BOT became well tolerated in 18 patients but remained not tolerated in 3. One of these 3 patients underwent PAO. The mean duration between the STA-MCA bypass and PAO was 14 days (range: 6 - 30). The endovascular procedure done was PAO with latex detachable balloons in 17 cases and with GDC in one case. One patient had partial embolization $(70 \%)$ of his aneurysm, another patient could not be treated as she refused the saphenous vein bypass graft, and one patient died before endovascular treatment. After the endovascular treatment, patients were admitted to the neurosurgical intensive care unit for 48 hours with complete bed rest. Patients were then followed up clinically and with serial skull $\mathrm{x}$-rays to verify that the balloons remained inflated. Post-procedure CT scans, MRIs, and DSAs were done at 1 week, 6 months, and then once a year to document disappearance of the aneurysm.

\section{Results}

\subsection{Clinical and Radiologic Data}

Table 3 summarizes the clinical and radiological features of the series. In total, 29 patients with GIAs have been treated by this approach during the study period. Nevertheless, only 21 medical records had enough data to allow objective evaluation. These comprised 16 female and 5 male patients bearing 21 GIA. Their mean age was 46 years. Mass effect revealed the aneurysm in 13 cases while SAH did so in 1 case. On admission, 19 patients had unruptured aneurysms and the two who ruptured their aneurysm were grade I at the WFNS scale (Table 1). The arterial circle of Willis was abnormal in $13(62 \%)$ patients. Eighteen patients did not tolerate the BOT while the 3 others had a functionally insufficient circle of Willis. The STA-MCA bypass could not be done in 1 patient due to the poor quality of his superficial temporal artery. After the STA-MCA bypass, the BOT was still not tolerated in 4 cases. The endovascular treatment was PAO with latex detachable balloons in 17 cases, with GDC in 1 case, and partial embolization of the aneurysm sac in 1 patient. One patient could not be treated as she refused the saphenous vein bypass graft, and 1 patient died before the endovascular treatment. The mean delay between the STA-MCA bypass intervention and the PAO was 14 days. Sixteen out of the 19 (84\%) patients fully treated had alleviation of all 
Table 3. Clinical and radiological features of the series.

\begin{tabular}{|c|c|c|}
\hline FEATURES & NUMBER (N) & PERCENTAGES (\%) \\
\hline Number of patients & 21 & 100 \\
\hline Number of GIAs & 21 & 100 \\
\hline \multicolumn{3}{|l|}{ Gender } \\
\hline Male & 5 & 23.80 \\
\hline Female & 16 & 76.20 \\
\hline Male: female ratio & $1: 3.2$ & \\
\hline \multicolumn{3}{|l|}{ AGE (years) } \\
\hline Mean (range) & $46(21-68)$ & \\
\hline \multicolumn{3}{|l|}{ Mode of revelation } \\
\hline Mass effect & 13 & 61.90 \\
\hline CN deficits & 06 & 28.57 \\
\hline Headaches & 04 & 19.04 \\
\hline Intracranial hypertension & 03 & 14.28 \\
\hline Seizures & 03 & 14.28 \\
\hline Incidental & 03 & 14.28 \\
\hline SAH; Ischemic stroke (each) & 01 & 04.76 \\
\hline \multicolumn{3}{|l|}{ Clinical manifestations } \\
\hline Headaches & 12 & 57.14 \\
\hline $\mathrm{CN}$ deficits & 09 & 42.85 \\
\hline SAH & 03 & 14.28 \\
\hline Seizures & 03 & 14.28 \\
\hline Diplopia & 02 & 09.52 \\
\hline Motor or sensitive deficit (each) & 01 & 04.76 \\
\hline \multicolumn{3}{|l|}{ Aneurysm features } \\
\hline Mean size (range) & $33.75 \mathrm{~mm}(26-42)$ & ----- \\
\hline Carotid-ophthalmic & 07 & 33.33 \\
\hline Cavernous sinus & 04 & 19.04 \\
\hline MCA & 05 & 23.80 \\
\hline Multiloculated & 07 & 33.33 \\
\hline Fusiform ${ }^{\star}$ & 05 & 23.80 \\
\hline Saccular & 05 & 23.80 \\
\hline Multiple & 03 & 14.28 \\
\hline Circle of Willis anomalies $\S$ & 13 & 61.90 \\
\hline \multicolumn{3}{|l|}{ Past medical history } \\
\hline Smoking & 08 & 38.09 \\
\hline Arterial hypertension & 03 & 14.28 \\
\hline Migraine headaches & 02 & 09.52 \\
\hline Family history of cerebral aneurysm & 01 & 04.76 \\
\hline Delay between STA-MCA bypass \& PAO (days) & $14(6-30)$ & \\
\hline \multicolumn{3}{|l|}{ Follow up (months) } \\
\hline Mean (range) & $30(6-72.5)$ & \\
\hline
\end{tabular}

GIA: giant intracranial aneurysm. CN: cranial nerve. SAH: subarachnoid hemorrhage. MCA: Middle cerebral artery. ${ }^{*}$ : dysplastic 2 cases, dissecting, one case. §: A1 segment, 6 cases; PCOM, 6 cases; PCA, 4 cases. Hypoplasia or atresia, 8 cases (A1, 5 cases). Agenesis, 5 cases (PCOM, 4 cases). PCOM: posterior communicating artery. PCA: posterior cerebral artery. A1: first segment of the anterior cerebral artery. 
symptoms (modified Rankin scale score 0). Overall, the outcome was favorable in $94.73 \%$ of the cases treated (18/19) although $3(16 \%)$ patients had treatment related sequels which were disabling in only one case. There was no aneurysmal recanalization or rupture after the $\mathrm{PAO}$ was performed.

The mean follow-up period was 30 months (range: 6 - 72.5). There was no procedure-related mortality but one patient (case \# 5) died the day preceding the PAO procedure by a dramatic rupture of his GIA (WFNS grade V; Fischer grade 4). The time between the STA-MCA bypass and PAO was abnormally long in this particular patient (30 days versus 14 days in average). We were not able to determine why such a long time elapsed between the two procedures.

Three complications occurred following the STA-MCA intervention: an unexplained transient aphasia (case $\mathrm{n}^{\circ} 3$ ); a small intracerebral hematoma at the site of the anastomosis with comprehension aphasia that completely resolved (case $n^{\circ} 4$ ); a SAH (WFNS grade I) with Broca's aphasia and motor weakness of the face and right upper limb with rapid complete resolution too (case $n^{\circ} 8$ ). Finally, there was no permanent morbidity related to the STA-MCA bypass procedure.

Four complications occurred after the endovascular procedure: decrease of visual acuity on the left eye (case $n^{\circ} 7$, partial embolization of the aneurysm); a left hemiplegia related to an infarct in the water-shaded area at day- 2 with almost complete resolution (case $\mathrm{n}^{\circ} 9, \mathrm{mRS}=1$ ); aphasia and right hemiplegia due to a Sylvian ischemia (case $\left.n^{\circ} 11, \mathrm{mRS}, 4\right)$; a motor deficit of the right upper limb that had completely regressed by day- 2 (case $\left.n^{\circ} 14\right)$.

In cases $\mathrm{n}^{\circ} 7$ and 11 , the BOT was still not tolerated disclosing an asynchronous filling both in the arterial and venous phases for patient 11, and aphasia for patient 7 despite patent STA-MCA bypasses. Maybe those two patients could benefit more from a high-flow bypass.

On the other hand, cases $n^{\circ} 9$ and 14 had an assumed well tolerated BOT, but patient 9 finally had minimal permanent deficit (mRS score 1), while patient 14 completely recover from his right arm weakness. Nevertheless, the mechanism underlying the decrease in visual acuity of case $\mathrm{n}^{\circ} 7$ was not clear. The follow-up MRIs and angiographies showed complete obliteration of the aneurysm in all patients treated by PAO. We observed neither recanalization nor rupture after PAO.

\subsection{The BOT}

After the STA-MCA bypass, the BOT was still not tolerated in 3 cases. One could not be treated as she refused the saphenous vein grafting proposed to her, another patient had partial embolization (70\%) of the aneurysm with no subsequent incident to date, and the other patient $\left(\mathrm{N}^{\circ} 11\right)$ underwent PAO with poor outcome.

Concerning the 18 patients who had a well-tolerated BOT, two of them $\left(\mathrm{N}^{\circ} 9\right.$ and 14) presented complications after PAO. The outcome was finally good for 
patient $9(\mathrm{mRS}=1)$, and excellent for patient $14(\mathrm{mRS}=0)$.

\subsection{Outcome}

The Figure 1 shows the clinical outcome as determined by the modified RS. The Figure 2 shows the quality of life appreciated by the patients and their medical doctors. Globally, at six month follow-up, 16 (84.21\%) out of the 19 patients who had full treatment were free of symptoms $(m R S=0)$, two had no significant disability and were able to carry out all usual duties $(\mathrm{mRS}=1)$, while one had a poor outcome $(\mathrm{mRS}=4)$. Overall, the outcome was good in $95 \%$ of treated patients $(18 / 19, \mathrm{mRS} \leq 1)$. The one death of the series occurred in a patient who did not have PAO after STA-MCA bypass and for who the delay between the bypass operation and the PAO was abnormally long.

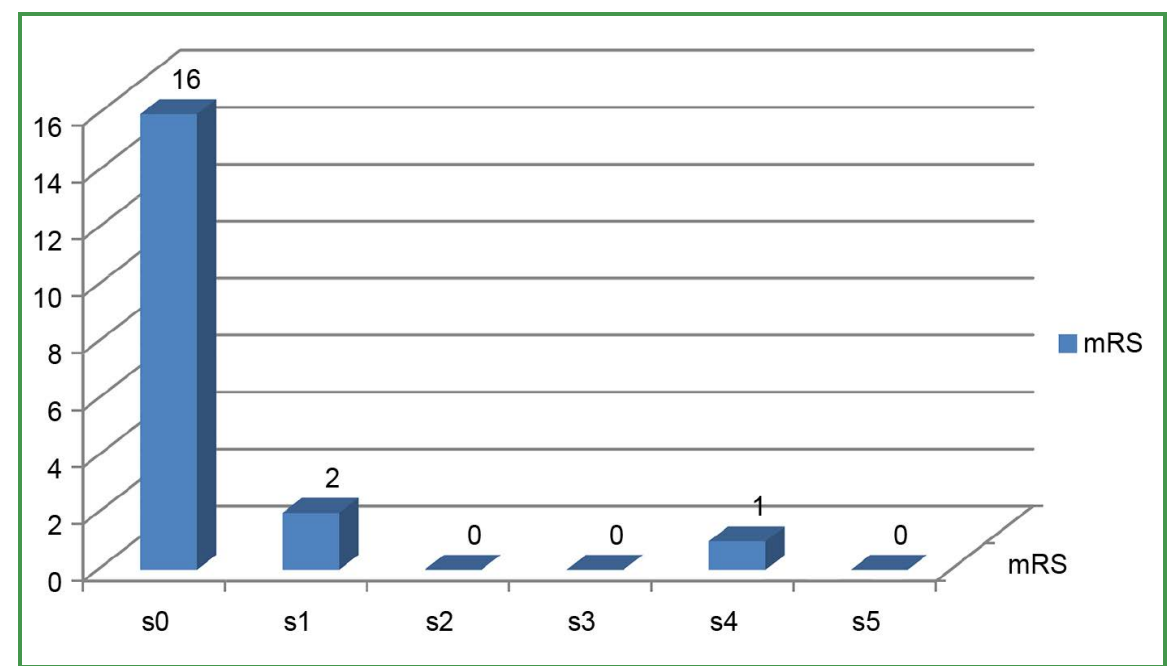

Figure 1. Outcome assessment with the modified Rankin scale at six-months of follow-up. mRS: modified Rankin scale. s0 - s5: score 0 to score 5.

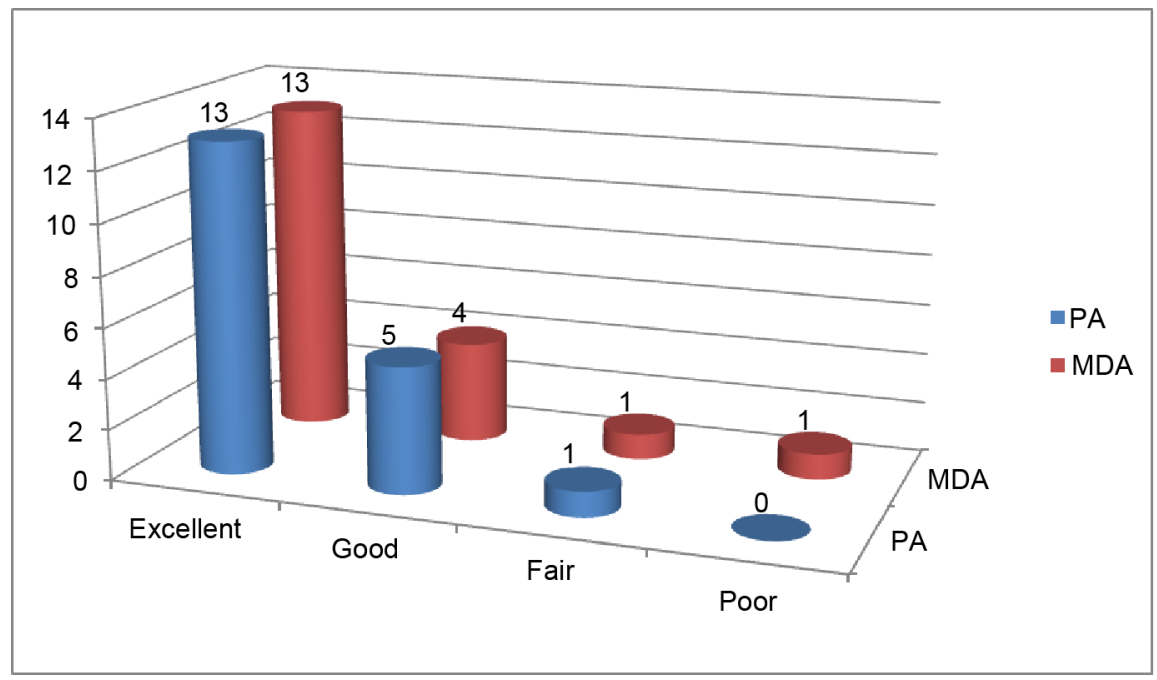

Figure 2. Post-treatment quality of life appreciated by the patients \& the medical Doctors. PA: patient appreciation. MDA: medical Doctor Appreciation. 


\subsection{Illustrative Clinical Case 1 (Figure 3)}

She was a 60-years-old woman with a past history of migraine headaches. She presented in May 1991 with sudden loss of vision on the left eye with headaches without a meningeal syndrome. The visual acuity was at $2 / 10$ with a defect in the left nasal eye field. The head CT-scan revealed a left paraclinoid round-shaped hyper dense mass with no visible blood in the subarachnoid spaces. The mass had approximately $18 \mathrm{~mm}$ of diameter. The MRI evoked a left carotid-ophthalmic aneurysm of about $25 \mathrm{~mm}$ of diameter, partially thrombosed, with a small contralateral aneurysm. Four vessels DSA confirmed the above findings. It was not possible to treat this aneurysm selectively. PAO was then contemplated, but the patient failed the BOT with delayed arterial and venous filling on the left side after injection of the right ICA. The STA-MCA bypass was done in June 1991 with no complication. The BOT was therefore repeated 11 days later with synchronous filling on both sides and a patent STA-MCA anastomosis. The left ICA was then occluded during the same procedure with no intraoperative complication. But, 2 days after PAO, the patient presented a motor weakness on the right upper limb that rapidly regressed. On day-7, the neurological examination was normal. The MRI revealed 2 lacunae in the right caudate and lentiform nuclei. This case illustrates the thrombo-embolic phenomena that can occur in the course of GIA, even after PAO.

\section{Clinical case 2 (Figure 4)}
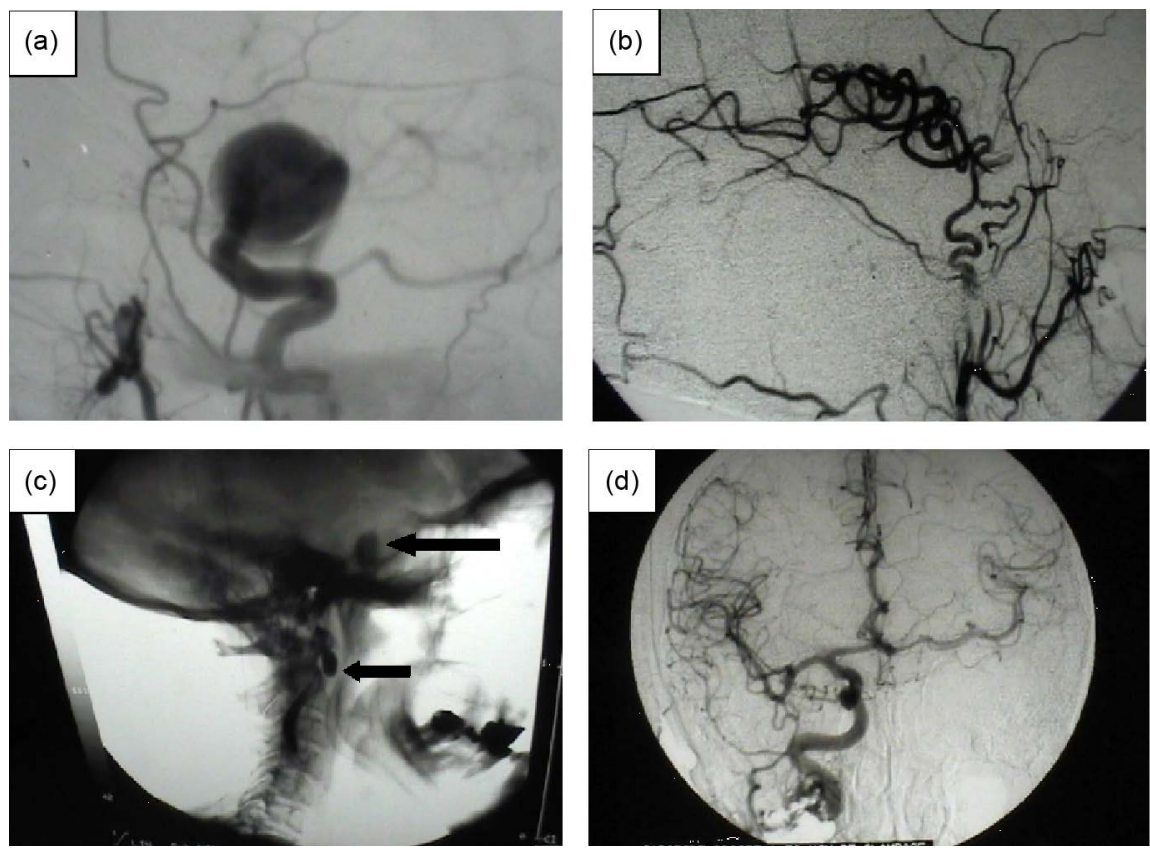

Figure 3. Patient 14. Sudden loss of vision with headaches in a 60 -year-old woman. (a) four vessels cerebral angiography showing a left carotid-ophthalmic GIA; (b) left external carotid angiogram showing a patent STA-MCA bypass; (c) lateral skull x-ray showing 2 balloons already detached (arrows); (d) right internal carotid angiogram 50 minutes after occlusion of the left internal carotid artery showing filling of the left Sylvian vessels by the STA-MCA bypass [courtesy from corresponding author]. 

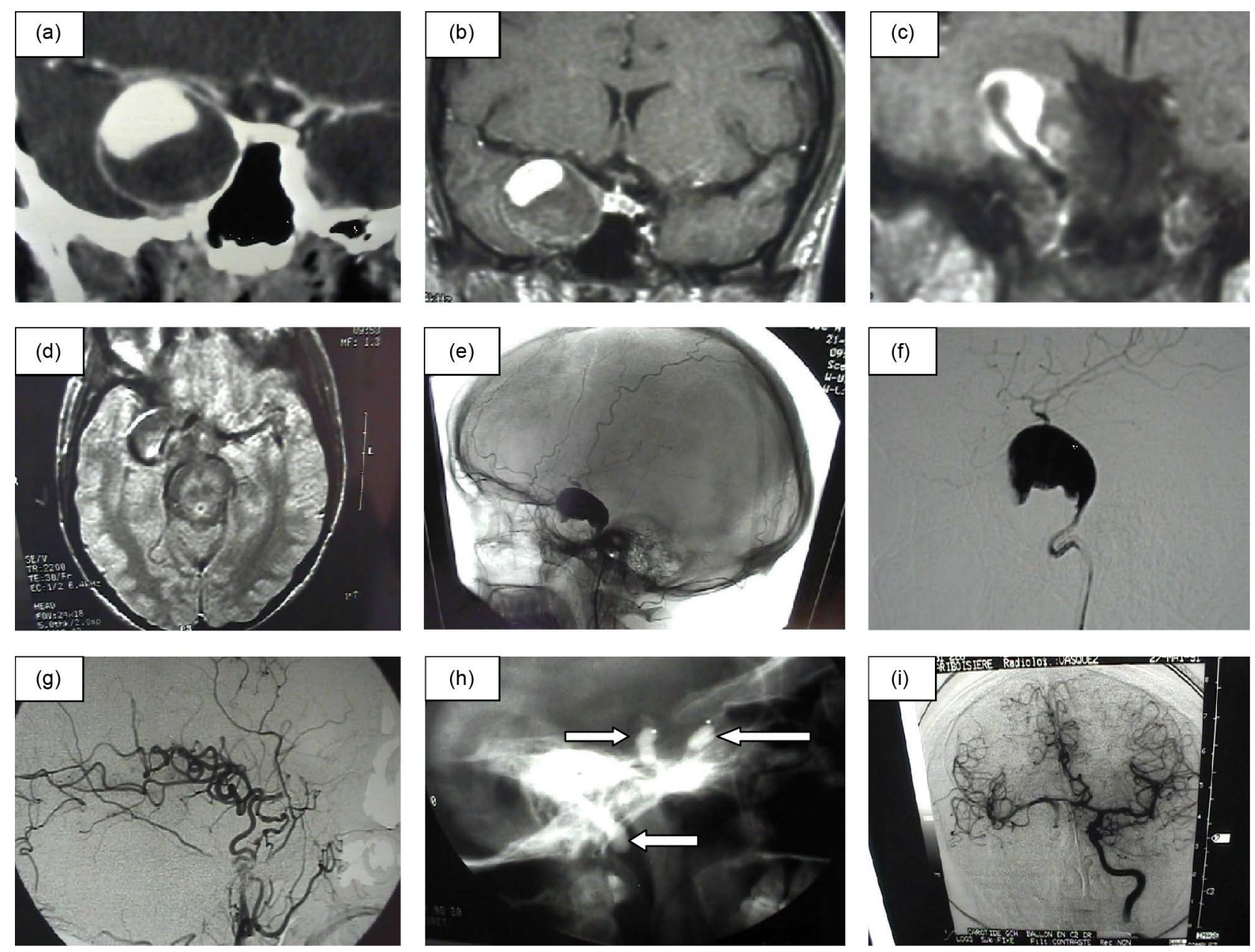

Figure 4. Patient 19. This 33-year-old woman presented with trigeminal neuralgia and Abducens nerve palsy on the right side. (a) brain CT-scan showing a partially thrombosed GIA within the right cavernous sinus; (b), (c), (d), MRI showing the right cavernous GIA with serpentine filling; (e), (f), right internal carotid artery angiograms showing the GIA; (g), right external carotid artery angiogram showing a patent STA-MCA bypass; (h), latex balloons already detached for occlusion of the right ICA (arrows); (i), left ICA angiogram after occlusion of the right ICA showing synchronous filling on both sides [courtesy from corresponding author].

\section{Discussion}

The dismal natural history of GIAs does not permit to consider treatment abstention as option unless the general status of the patient does not allow any invasive procedure [6] [7]. Nowadays, flow-diversion is probably the first option to contemplate when dealing with GIAs [1] [3] [4]. This was not the case when this series was going on. Selective methods, either endovascular or microsurgical should be the treatments of first intention. When they had failed, non-selective methods such as $\mathrm{PAO}$ with a previous preventive revascularization when necessary should then be contemplated. Because of lack of class I evidence and multiple biases in published data [2] [5], all treatment modalities remain on the table when dealing with GIAs. We agree with Sekhar et al. who think that the optimal treatment of a GIA can be offered to patients only by multidisciplinary teams with expertise in both endovascular and microvascular neurosurgery and who 
master all aspects of the different treatment modalities [5]. Some authors [9] [14] had suggested that PAO could be the treatment of choice for GIAs because selective embolization is not often curative. In the series from Ross [9], among 10 patients who were treated with selective embolization, only one patient was cured, after spontaneous occlusion of the parent artery following embolization. Conversely, the 9 cases treated by PAO were all cured. In the series of Hans Henkes [8], PAO achieved the highest rate of total or near total obliteration of the aneurysm $(90 \%-100 \%)$ while the morbidity related to that procedure was among the lowest. Furthermore, the recanalization rate after coil embolization of large and giant aneurysms in that series was as high as $90 \%$. In our point of view, selective treatment with preservation of afferent and efferent vessels should remain the first treatment whenever possible. Keen, cited by Cloft was the first to treat an intracranial aneurysm by hunterian ligation of the internal carotid artery [6]. Subsequently, selective surgical and endovascular treatment had proved superior to PAO. But, it rapidly appeared that not all aneurysms were suitable to selective treatments, hence, PAO was still a viable option. Today, endovascular PAO had supplanted surgical ligation. In this series, the combination of STA-MCA bypass with endovascular PAO has permitted to cure $90 \%(19 / 21)$ of patients bearing GIAs that were untreatable by other means with results being excellent $(\mathrm{mRS}=0)$ in $84 \%(16 / 19)$ and good in 95\% $(18 / 19)$ of the cases. The treatment-related morbidity was permanent in $3(16 \%)$ cases, being disabling in only 1 case $(\mathrm{mRS}=4)$ on a patient who still not tolerated the BOT in spite of a patent STA-MCA bypass. Other authors [9] [15] recommend, as we did, to pursue with PAO even in the presence of a BOT that has failed if there is no other choice than therapeutic abstention. The one death of this series concerned a patient who ruptured his aneurysm before $\mathrm{PAO}$ and in who the interval between the STA-MCA bypass and the planned PAO was unusually long (30 days versus 14 days in average). In agreement with Zhao et al. [2], we think that the STA-MCA bypass will be sufficient in most cases for preventive revascularization in treating GIAs. So, the other bypass methods which carry more risks should be reserved to those cases that still fail the BOT in the presence of a patent STA-MCA anastomosis. Two patients ruptured their aneurysm following the STA-MCA procedure. This complication has been reported by others [16] [17], but, spontaneous thrombosis of an aneurysm after a bypass intervention has also been reported [18]. There was neither aneurysm recanalization nor rupture after PAO in this series. The defaults of occlusion tests and the different means used to make them more accurate have been emphasized by many authors [10] [11] [15] [19]-[24].

That was the debate before the introduction of flow diverters to clinical practice. Today, it is clear that FD is the first choice option while dealing with complex IAs and hence, GIAs. It was amazing for us to compare FD which has brought a new paradigm for managing GIAs, to this endovascular PAO series. The result was surprising and not so in favor of FD. As one can see in Table 4, FD was not superior to PAO in terms of technical feasibility, complete aneurysmal 
Table 4. Outcomes comparison between PAO of the series \& FD data from the literature [1] [2] [3] [4] [5].

\begin{tabular}{ccc}
\hline OUTCOME & ENDOVASCULAR PAO & FLOW-DIVERSIONS \\
\hline Technical feasibility & $90 \%$ & $90 \%-100 \%$ \\
Complete occlusion rates & $100 \%$ & $76 \%(50 \%-94 \%)$ \\
Good outcome & $95 \%$ & $87 \%-95 \%$ \\
Postoperative SAH & $0 \%$ & $19 \%(2 \%-34.5 \%)$ \\
Postoperative TEE & $17 \%$ & $9 \%(3 \%-15 \%)$ \\
Mortality & $0 \%$ & $6 \%(0 \%-12 \%)$ \\
Permanent Morbidity & $16 \%$ & $12.5 \%(0 \%-25 \%)$ \\
\hline
\end{tabular}

PAO: parent artery occlusion. FD: flow-diversion. SAH: subarachnoid hemorrhage. TEE: thrombo-embolic events. *: outcomes for the present series. $\S$ : flow diversion related mortality and morbidity are higher with ruptured aneurysms, posterior circulation aneurysms (mortality and morbidity close to $50 \%$ in early experience), distal anterior circulation aneurysms and blister-like aneurysms.

occlusion rates, procedure-related mortality and morbidity and good outcomes. Furthermore, PAO did not expose patients to delayed complications related to FD such as delayed thromboembolic events and aneurysmal rupture, though aneurysmal rupture can arise following a bypass operation. Moreover, FD can cause parent artery, perforators or arterial branches stenosis in up to $33 \%$ of the cases [2] [4] [5]. Also, FD mortality and morbidity are higher with ruptured aneurysms, posterior circulation aneurysms (up to 50\% reported mortality [1]), distal anterior circulation aneurysms and blister-like aneurysms. But, as a new technique, flow-diversion has the advantage of being a single stage procedure which has tremendously simplified the management of the challenging lesions that are GIAs. In the future, some patients might need a previous bypass operation before undergoing a FD intervention in the management of their complex IAs.

\section{Conclusion}

The advent of flow diversion has revolutionized the treatment of complex intracranial aneurysms in general and GIAs in particular. In the very near future, flow-diversion will probably become the first treatment option for the management of complex IAs. It is obvious that most GIAs of this series would have been successfully treated with FD. In this series, $90 \%$ of GIAs are not suitable for selective methods could be definitely treated by STA-MCA bypass combined to endovascular PAO and achieving a good neurological outcome (mRS $0-1)$ in $95 \%$ of the patients. Moreover, the results from this "old series and treatment modality" are comparable to the most recent flow-diversion series in terms of technical feasibility, complete aneurysmal occlusion rates, procedure-related mortality and morbidity and favorable outcomes. Since the optimal treatment of GIAs is yet to be defined, endovascular PAO with or without a previous EC-IC bypass might still be the best option for any single patient with a GIA. 


\section{Conflict of Interest}

No funding was received by the authors from third parties in relation with the present study.

\section{References}

[1] Brouillard, A.M., Sun, X., Siddiqui, A.H. and Lin, N. (2016) The Use of Flow Diversion for the Treatment of Intracranial Aneurysms: Expansion of Indications. $\mathrm{Cu}$ reus, 8, e472.

[2] Zhao, J., Lin, H., Summers, R., Yang, M., Cousins, B.G. and Tsui, J. (2017) Current Treatment Strategies for Intracranial Aneurysms: An Overview. SAGE Journals. http://journals.sagepub.com/doi/10.1177/0003319717700503

[3] Alderazi, Y.J., Shastri, D., Kass-Hout, T., Prestigiacomo, C.J. and Gandhi, C.D. (2014) Flow Diverters for Intracranial Aneurysms. Stroke Research and Treatment, 2014, 12. https://doi.org/10.1155/2014/415653

[4] Brinjikji, W., Murad, M.H., Lanzino, G., Cloft, H.J. and Kallmes, D.F. (2013) Endovascular Treatment of Intracranial Aneurysms with Flow Diverters. A Meta-Analysis. Stroke, 44, 442-447. https://doi.org/10.1161/STROKEAHA.112.678151

[5] Sekhar, L.N., Tariq, F., Mai, J.C., Kim, L.J., Ghodke, B., Hallam, D.K. and Bulsara, K.R. (2012) Unyielding Progress: Treatment Paradigms for Giant Aneurysms. Clinical Neurosurgery, 59, 6-21. https://doi.org/10.1227/NEU.0b013e3182698b75

[6] Cloft, H.J. (2002) Parent Vessel Occlusion for Cerebral Aneurysms and Pseudo Aneurysms. In: Michael, H.M.D. and Marks, P., Ed., Endovascular and Percutaneous Therapy of the Brain and Spine. Lippincott Williams and Wilkins, Philadelphia, 163-181.

[7] Lemole, G.M., Jeffrey, J., Henn, S., Spetzler, R.F. and Riina, H.A. (2004) Surgical management of Giant Cerebral Aneurysms, in Management of Cerebral Aneurysms. In: Peter, H.R.W., Leroux, D. and Newell, D.W., Eds., Saunders, Philadelphia, 659-688.

[8] Hans Henkes, S.F., Werner Weber, W., Miloslavski, E., Felber, S., Brew, S. and Kuehne, D. (2004) Endovascular Coil Occlusion of 1811 Intracranial Aneurysms: Early Angiographic and Clinical Results. Neurosurgery, 54, 268-285. https://doi.org/10.1227/01.NEU.0000103221.16671.F0

[9] Ian, B., Ross, A.W., Piotin, M. and Moret, J. (2000) Endovascular Treatment of Distally Located Giant Aneurysms. Neurosurgery, 47, 1147-1153. https://doi.org/10.1097/00006123-200011000-00025

[10] van Rooij, W.J.J., Sluzewski, M., Metz, N.H., Nijssen, P.C.G., Wijnalda, D., Rinkel, G.J.E. and Tulleken, C.A.F. (2000) Carotid Balloon Occlusion for Large and Giant Aneurysms: Evaluation of a New Test Occlusion Protocol. Neurosurgery, 47, 116-122.

[11] Jonathan, E., Hodes, A.A., Pierre Gobin, Y., Rüfenacht, D., Bien, S., Reizine, D., Gaston, A. and Merland, J.J. (1991) Endovascular Occlusion of Intracranial Vessels for Curative Treatment of Unclippable Aneursysms: Report of 16 Cases. Journal of Neurosurgery, 75, 694-701. https://doi.org/10.3171/jns.1991.75.5.0694

[12] Newell, D.W. (2004) Superficial Temporal Artery to Middle Cerebral Artery Bypass. Neurosurgery, 54, 1441-1449. https://doi.org/10.1227/01.NEU.0000124754.84425.48

[13] Wanebo, J.E., Zabramski, J.M. and Spetzler, R.F. (2004) Superficial Temporal Artery-To-Middle Cerebral Artery Bypass Grafting for Cerebral Revascularization. Neurosurgery, 55, 395-399. https://doi.org/10.1227/01.NEU.0000129549.99061.94

[14] Gobin, Y.P., Viñuela, F., Gurian, J.H., Guglielmi, G., Duckwiler, G.R., Massoud, 
T.F. and Martin, N.A. (1996) Treatment of Large and Giant Fusiform Intracranial Aneurysms with Guglielmi Detachable Coils. Journal of Neurosurgery, 84, 55-62. https://doi.org/10.3171/jns.1996.84.1.0055

[15] Vallee, J.N., Casasco, A.E., Jhaveri, H.S., Houdart, E. and Merland, J.-J. (1999) Endovascular Test and Permanent Occlusion of Extracranial and Intracranial Cerebral Vessels: Indications, Techniques, and Management. In: Connors, J.C.W. and Connors, J.J., Eds., Interventional Neuroradiology. Strategies and Practical Techniques. W.B. Saunders Company, Philadelphia, 394-407.

[16] Anson, J.A., Stone, J.L. and Crowell, R.M. (1991) Rupture of a Giant Carotid Aneurysm after Extracranial-to-Intracranial Bypass Surgery. Neurosurgery, 28, 142-147.

[17] Chang, S.D., Marks, M.P. and Steinberg, G.K. (1999) Recanalization and Rupture of a Giant Vertebral Artery Aneurysm after Hunterian Ligation: Case Report. Neurosurgery, 44, 1117-1121. https://doi.org/10.1097/00006123-199905000-00101

[18] Cantore, G., Santoro, A. and Da Pian, R. (1999) Spontaneous Occlusion of Supraclinoid Aneurysm after the Creation of Extra-Intracranial Bypasses Using Long Grafts: Report of Two Cases. Neurosurgery, 44, 216-219. https://doi.org/10.1097/00006123-199901000-00132

[19] Connors, J.J. (1999) Temporary Test Occlusion of the Internal Carotid Artery. In: Connors, J.C.W. and Connors, J.J., Eds., Interventional Neuroradiology, Strategies and Practical Techniques, W.B. Saunders Company, Philadelphia, 377-390.

[20] Connors, J.J. (1999) Permanent Occlusion of the Internal Carotid Artery. In: Connors, J.C.W. and Connors, J.J., Eds., Interventional Neuroradiology, Strategies and Practical Techniques, W.B. Saunders Company, Philadelphia, 390-394.

[21] Jafar, J.J., Henry, S.M.R. and Woo, H. (2002) Treatment of Giant Intracranial Aneurysms with Saphenous Vein Extracranial-to-Intracranial Bypass Grafting: Indications, Operative Technique, and Results in 29 Patients. Neurosurgery, 51, 138-146. https://doi.org/10.1097/00006123-200207000-00021

[22] Teasdale, G.M., Drake, C.G., Hunt, W., Kassell, N., Sano, K., Pertuiset, B. and De Villiers, J.C. (1988) A Universal Subarachnoid Hemorrhage Scale: Report of a Committee of the World Federation of Neurosurgical Societies. Journal of Neurology, Neurosurgery, and Psychiatry, 51, 1457-1463.

https://doi.org/10.1136/jnnp.51.11.1457

[23] Hunt, W.E. and Hess, R.M. (1968) Surgical Risk as Related to Time of Intervention in the Repair of Intracranial Aneurysms. Journal of Neurosurgery, 28, 14-20. https://doi.org/10.3171/jns.1968.28.1.0014

[24] Fisher, C.M., Kistler, J.P. and Davis, J.M. (1980) Relation of Cerebral Vasospasm to Subarachnoid Hemorrhage Visualized by CT Scanning. Neurosurgery, 6, 1-9. https://doi.org/10.1227/00006123-198001000-00001

[25] Sulter, G., Steen, S. and De Keyser, J. (1999) Use of the Barthel and Modified Rankin Scale in Acute Stroke Trials. Stroke, 30, 1538-1541. https://doi.org/10.1161/01.STR.30.8.1538

[26] Banks, J.L. and Marotta, C.A. (2007) Outcomes Validity and Reliability of the Modified Rankin Scale: Implications for Stroke Clinical Trial. Stroke, 38, 1091-1096. https://doi.org/10.1161/01.STR.0000258355.23810.c6

[27] Lindsay Wilson, J.T., Hareendran, A., Hendry, A., Potter, J., Bone. I. and Muir, K.W. (2005) Reliability of the Modified Rankin Scale across Multiple Raters. Benefits of a Structured Interview. Stroke, 36, 777-781. https://doi.org/10.1161/01.STR.0000157596.13234.95 


\section{Abbreviations Used in This Article}

BOT/BTO: balloon occlusion test/balloon test occlusion. CHU: Centre Hospitalier Universitaire (University Teaching Hospital). CN: cranial nerve. CT: computed tomography. CTA: computed tomography angiography. DSA: digital subtractive angiography. EC-IC: extracranial to intracranial. GIA: giant intracranial aneurysm. IA: intracranial aneurysm. ICP: intracranial pressure. OA: occipital artery. PAO: parent artery occlusion. MCA: middle cerebral artery. MRI: magnetic resonance imaging. MRA: magnetic resonance angiography. STA: superficial temporal artery. GDC: Guglielmi detachable coil. SAH: subarachnoid hemorrhage. mRS: modified Rankin scale. TCD: transcranial Doppler. WFNS: world federation of neurosurgical societies. 